\title{
Análise ambiental e econômica para instalação de uma planta de biodigestão em uma comunidade isolada do Brasil
}

\author{
Environmental and economic analysis for the installation of a \\ biodigestion plant in an isolated community in Brazil
Maria Luiza Grillo Renó ${ }^{*} \oplus^{\oplus}$, Pedro Jessid Pacheco Torres ${ }^{2} \oplus$, Taís Eliane Marques ${ }^{1} \oplus$, Natalia de Souza Ribeiro' 1 (1)

\begin{abstract}
口-
RESUMO

Este trabalho analisa, dos pontos de vista ambiental e econômico, uma proposta de geração de eletricidade usando resíduos agrícolas, com a tecnologia da biodigestão anaeróbica. A área selecionada para tal proposta foi uma comunidade isolada da Região Norte do Brasil, cuja fonte de geração elétrica é uma planta que opera com o combustível diesel. Os resultados mostraram que a alternativa proposta apresenta alto custo em comparação com a planta diesel, porém terá menos impactos ambientais (com relação às emissões atmosféricas) e menor custo referente ao consumo de combustível, pois os resíduos são agrícolas.
\end{abstract}

Palavras-chave: biodigestão; impactos ambientais; comunidade isolada.

\begin{abstract}
This paper analyzed, from an environmental and economic point of view, a proposal for electricity generation using agricultural residues, with anaerobic biodigestion technology. The area selected for such proposal was an isolated community in the North of Brazil, whose source of electrical generation is a plant operating with diesel fuel. The results showed that the proposed alternative presents a high cost in comparison to the diesel plant, but the alternative will cause less environmental impacts (in relation to atmospheric emissions) and lower costs related to fuel consumption, since they are agricultural residues.
\end{abstract}

Keywords: biodigestion; environmental impacts; isolated community.

\section{INTRODUÇÃO}

Atualmente, o mercado mundial de energia é dominado pelos combustíveis fósseis. A literatura mostra que mais de $70 \%$ da oferta global de eletricidade é suprida com o uso de carvão, óleo combustível e gás natural. Um exemplo é a Região Norte do Brasil, na qual 95\% da geração elétrica é proveniente de fontes fósseis. Nas comunidades isoladas da mesma região, o diesel tem representativa participação na geração de eletricidade, correspondendo a $80 \%$ do consumo de combustível desses locais (TORRES, 2017).

Logo, para tais regiões isoladas o uso da biomassa como fonte energética pode ser uma opção rentável e benéfica ao meio ambiente. Isso principalmente para regiões onde há atividades agrícolas, pois assim se aproveitariam os resíduos dessas atividades para a geração de eletricidade.

Com a finalidade de prover uma opção de geração de energia que não fique limitada ao fornecimento de combustíveis fósseis, apresenta-se neste trabalho uma análise ambiental e econômica de geração de eletricidade com o uso de resíduos agrícolas numa comunidade isolada do Brasil.

\section{METODOLOGIA}

\section{Estudo de caso}

O Brasil é composto de cinco regiões. A Região Norte é a que possui maior extensão territorial, com 3,854 milhões de quilômetros quadrados, e se caracteriza pela presença marcante de comunidades isoladas, formadas principalmente de pescadores, extrativistas, seringueiros, ribeirinhos, índio e agricultores. A característica desse grupo é a carência de eletricidade, educação, saúde e recursos financeiros (BRITO NETO, 2006).

A geração de energia elétrica nessas comunidades normalmente é realizada em pequenas unidades geradoras a óleo diesel, que muitas vezes apresentam grandes dificuldades para o abastecimento. Um exemplo é o município de Altamira (estado do Pará), abastecida por uma pequena central termelétrica de potência instalada de $80 \mathrm{~kW}$, que opera com óleo diesel como combustível (ANEEL, 2014).

Essa cidade tem grande potencial de geração de eletricidade com o uso de resíduos agrícolas pela grande disponibilidade desses resíduos decorrente dos cultivos presentes no local, como mostra a Figura 1 (TORRES, 2017):

'Universidade Federal de Itajubá - Itajubá (MG), Brasil.

${ }^{2}$ Corporacion Universitaria Reformada - Barranquilla, Atlantico, Colômbia.

*Autora correspondente: malureno@yahoo.com.br

Conflitos de interesse: os autores declaram não haver conflito de interesses.

Financiamento: nenhum.

Recebido: 11/02/2019 - Aceito: 02/06/2020 - Reg. ABES: 20190042 
Na Figura 1, observa-se que os resíduos de banana e mandioca são os de maior quantidade: 20.956 e 14.560 ton.ano ${ }^{-1}$, respectivamente. Por esse motivo foram selecionados para o sistema de produção de eletricidade.

\section{Sistema de biodigestão}

Para atender à demanda do município de Altamira, foi proposto um sistema de biodigestão de $100 \mathrm{~kW}$ que operaria com os resíduos da banana e da mandioca. Nas instalações que usam sistemas de biodigestão de biomassa em pequena escala, a geração de energia é feita por um motor de combustão interna, como mostra a Figura 2.

Na Figura 2, o sistema completo apesenta pré-tratamento da matéria-prima, biodigestor, sistema de limpeza de gás, armazenamento de resíduos e

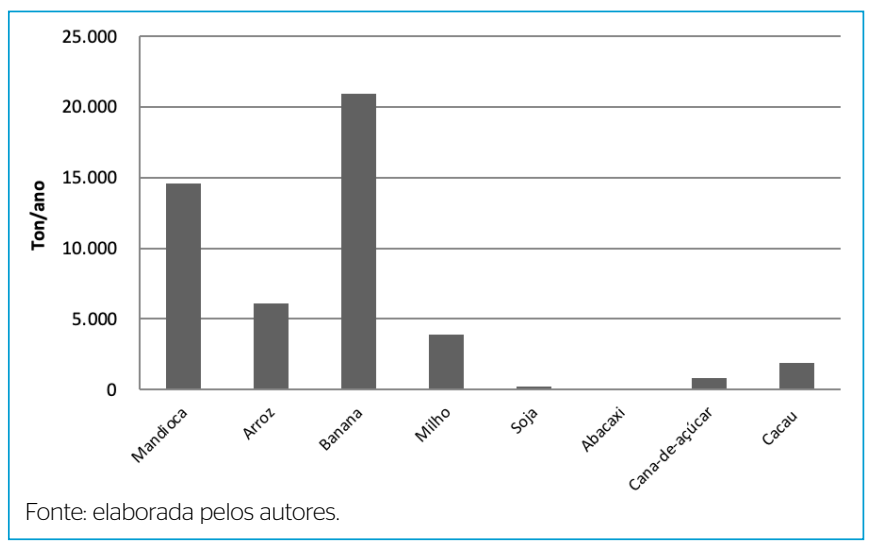

Figura 1 - Resíduos agrícolas da cidade de Altamira. motor gerador. O pré-tratamento térmico foi selecionado neste trabalho por ser mais aplicado para resíduos agrícolas. O processo consiste em submeter o resíduo a altas temperaturas $\left(>100^{\circ} \mathrm{C}\right)$ e pressões elevadas. Como consequência, os componentes de grande peso molecular dos resíduos são solubilizados ou degradados em outros mais simples, facilitando sua degradação pelos microrganismos (CARAPINHA, 2012).

Dentro do digestor anaeróbico ocorre uma sequência de processos, como a hidrólise, que consiste na quebra de complexas moléculas orgânicas insolúveis em moléculas solúveis por bactérias fermentativas. Em seguida, vêm as etapas acidogênese e acetogênese. A primeira é um processo de conversão de moléculas solúveis em ácidos graxos voláteis, hidrogênio e dióxido de carbono. Na segunda etapa os ácidos graxos voláteis são convertidos em ácido acético, hidrogênio e dióxido de carbono. Na etapa final, metanogênese, as bactérias metanogênicas convertem o acetato em metano e dióxido de carbono (COGAN; ANTIZARLADISLAO, 2016; MANI; SUNDARAM; DAS, 2016).

Após a digestão anaeróbica, o biogás precisa ser limpo para remover componentes tóxicos e prejudiciais como sulfeto de hidrogênio, amônia, compostos orgânicos voláteis, partículas e outros. As técnicas de limpeza atualmente utilizadas são adsorção, biofiltração e refrigeração. O processo de adsorção remove os contaminantes em um material poroso, a biofiltração remove sulfeto de hidrogênio e a umidade é removida pelo resfriamento do gás para condensar a água que pode ser drenada do sistema (ONG; WILLIAMS; KAFFKA, 2014). Após o sistema de limpeza, o biogás é enviado para queima num motor de combustão interna alternativo, produzindo assim eletricidade. Os sólidos e líquidos produzidos durante a digestão anaeróbica podem ser separados por gravidade. Trata-se de um método de baixo custo e simples tecnologia (AMARAL et al., 2016).

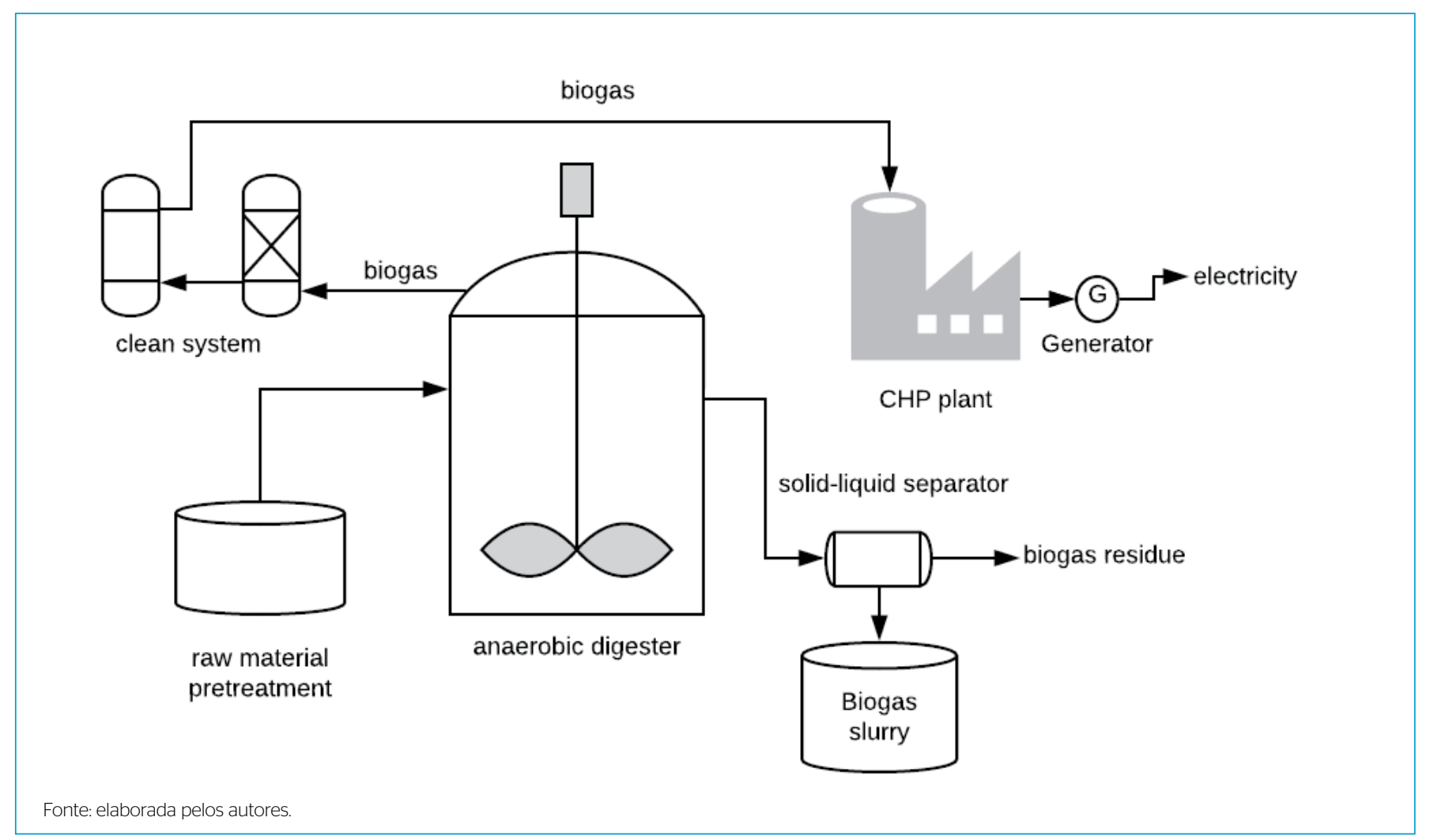

Figura 2 - Sistema de biodigestão. 


\section{Método de avaliação econômica}

Para analisar a viabilidade do sistema, foi calculado o valor presente líquido (VPL), indicador que mostra a viabilidade econômica do projeto durante seu período de vida útil. Esse indicador é definido pelo valor atual dos benefícios recebidos menos o valor dos custos do sistema. A Equação 1 apresenta o cálculo do VPL (ZIZLAVSKY, 2014):

$V P L=\sum_{t=0}^{n} \frac{B_{p}-C_{p}}{(1+r)^{t}}$

Em que:

$\mathrm{Bp}=$ benefício do projeto (US\$ durante $\mathrm{o}$ ano $\mathrm{t}$ );

$\mathrm{Cp}=$ custo do projeto (US\$ durante o ano $\mathrm{t}$ );

$\mathrm{r}=$ taxa de desconto (juros);

$\mathrm{t}=$ período (anos);

$\mathrm{n}=$ vida útil do investimento (anos).

Outro indicador aplicado foi a taxa interna de retorno (TIR), que consiste em determinar o cálculo da taxa que faz com que o VPL do fluxo de caixa das alternativas de investimento consideradas seja igualado a zero.

\section{Método de avaliação ambiental}

Para avaliar os impactos ambientais gerados durante a construção da planta, foi feita a análise de ciclo de vida (ACV). De acordo com a Associação Brasileira de Normas Técnicas/ Norma Brasileira da Organização Internacional de Normalização (ABNT NBR ISO) 14040 (ABNT, 2009), a ACV enfoca os aspectos ambientais e os impactos ambientais potenciais ao longo de todo o ciclo de vida de um produto, desde aquisição de matérias-primas, produção e uso até tratamento pós-uso e disposição.

A ACV é composta das seguintes etapas:

- definição do objetivo e escopo;

- análise de inventário;

- avaliação de impactos;

- interpretação.

Neste estudo, o objetivo é analisar os potenciais impactos ambientais na construção de um sistema de biodigestão. Para tal, é necessário um inventário das principais entradas (matéria-prima e combustível) e saídas (emissões, resíduos sólidos e líquidos), como também a definição de quais etapas do sistema de biodigestão estão limitadas pelas fronteiras.

Neste caso, o sistema de fronteiras abrange as etapas de pré-tratamento, digestão anaeróbica e armazenagem do biogás. A escolha destas deve-se à limitação de referências que apresentam os inventários de todas as etapas, contudo o resultado é válido, pois se considera o sistema de biodigestão, classificado como principal consumidor de recursos energéticos e minerais. A unidade funcional selecionada foi uma planta de biodigestão.

Para determinar os impactos ambientais, foi aplicado o método ReCiPe, que é baseado nos métodos Eco-Indicador 99 e CML 2002, com a remodelagem e atualização das categorias de impacto. A vantagem desse método é a maior quantidade de categorias de impacto determinadas em comparação aos demais métodos.
Neste trabalho também foi feita a etapa de normalização, que consiste no cálculo da magnitude das categorias de impacto calculadas em relação às informações de referência. Infelizmente não há referência para dados de regiões brasileiras, apenas resultado anual para áreas geográficas da Europa ou do mundo em geral.

\section{RESULTADOS E DISCUSSÃO}

\section{Parâmetros do sistema}

Um dos fatores mais importantes da biodigestão de resíduos é a taxa de produção de biogás. O potencial de produção de biogás com o uso dos resíduos é de $0,40 \mathrm{~m}^{3} \cdot \mathrm{kg}^{-1} \mathrm{de}$ sólidos voláteis (SV). O percentual de SV para os resíduos analisados neste trabalho é de aproximadamente $85 \%$, e o percentual de sólidos totais é em torno de 30\% (SEADI, 2008). Para o cálculo do índice de quantidade de biogás gerada, éutilizada a Equação 2.

$\mathrm{I}_{\text {biogás }}=\mathrm{P}_{\mathrm{B}} * \mathrm{ST} * \mathrm{SV}$

Em que:

$\mathrm{I}_{\text {biogás }}=$ quantidade de biogás produzido $\left(\mathrm{m}^{3} \cdot \mathrm{kg}^{-1}\right.$ biomassa $)$;

$\mathrm{P}_{\mathrm{B}}=$ potencial de produção de biogás $\left(\mathrm{m}^{3} \cdot \mathrm{kg}^{-1} \mathrm{SV}\right)$;

$\mathrm{ST}=$ sólidos total (\%);

SV = sólidos voláteis (\%).

Substituindo os valores numéricos na Equação 2, obtém-se o resultado $\mathrm{I}_{\text {biogás }}$ igual a $0,102 \mathrm{~m}^{3}$ biogás. $\mathrm{kg}^{-1}$ biomassa. Analisando agora a queima do biogás no motor de combustão já mencionado de $100 \mathrm{~kW}$, com eficiência de $24 \%$, a geração de energia elétrica será de $832.200 \mathrm{kWh}$ durante o ano, para um consumo de 0,208 milhões de $\mathrm{m}^{3}$ de biogás.ano-1 ${ }^{-1}$ (TORRES, 2017).

A disponibilidade de biomassa do município é de 35.516 ton.ano ${ }^{-1}$ (resíduos de banana e mandioca), o que resulta em uma produção de biogás de 3.662 .632 $\mathrm{m}^{3}$ por ano, caso todo o resíduo fosse aplicado no sistema de biodigestão. Como a demanda é de 0,208 milhões de $\mathrm{m}^{3}$.ano ${ }^{-1}$, o consumo de resíduos será de 2.039 ton.ano ${ }^{-1}$, ou $5,7 \%$ da disponibilidade de resíduos.

\section{A análise da viabilidade econômica}

De acordo com a literatura, os custos de uma planta de geração elétrica dividem-se em diversos tipos, que estão relacionados ao custo total do investimento (US\$ 963.200 para uma planta de biodigestão de $100 \mathrm{~kW}$ ), como apresentado na Tabela 1.

Tabela 1 - Principais custos de uma planta de biodigestão de 100 kW.

\begin{tabular}{l|c|c} 
Custos & $\begin{array}{c}\text { Custo total de } \\
\text { investimento } \\
(\%)\end{array}$ & $\begin{array}{c}\text { Custo total de } \\
\text { investimento } \\
\text { (US\$) }\end{array}$ \\
\hline Investimento do equipamento gerador & 53 & 510.496 \\
\hline Operação e manutenção & 4 & 38.528 \\
\hline Instalação do equipamento & 14 & 134.848 \\
\hline Tubulações & 7 & 67.424 \\
\hline Instrumentação e equipamentos de controle & 4 & 38.528 \\
\hline Equipamentos elétricos e materiais & 7 & 67.424 \\
\hline Construções civis & 11 & 105.952 \\
\hline Total & 100 & 963.200
\end{tabular}

Fonte: Torres (2017). 
Calculando os mesmos custos para uma usina a óleo diesel com a mesma capacidade (100 kW), chegou-se ao valor de US\$314.037. Isso demonstra que atualmente a implantação de um sistema de biodigestão tem alto custo, comparado ao da usina a óleo diesel.

Agora, para obter os resultados de VPL e TIR foram selecionadas duas taxas mínimas de atratividade: 12 e 15\%. A justificativa para tais taxas é serem consideradas para cenários mais realistas, com as condições econômicas atuais no Brasil. O tempo operacional é correspondente a $95 \%$ do ano, que equivale ao tempo necessário para atender a demanda energética da população. O resultado está apresentado na Tabela 2.

\section{Avaliação ambiental}

Conforme já mencionado anteriormente, foi feita a análise de ciclo de vida da construção de uma planta de produção de biogás incluindo a etapa de pré-tratamento e armazenagem do biogás. A planta está projetada para operar por 20 anos e os equipamentos têm um tempo de vida de 10 anos. O digestor anaeróbico tem uma capacidade máxima de $300 \mathrm{~m}^{3}$. A seguir, na Tabela 3, está apresentado o inventário de ciclo de vida referente à unidade funcional: uma planta de biodigestão.

Os impactos ambientais obtidos e normalizados aplicando o método ReCiPe estão apresentados na Figura 3.

Na Figura 3, pode-se notar que o impacto ambiental mais expressivo foi a depleção de metal, que ocorre em virtude dos recursos minerais consumidos na construção da planta. A transformação do solo é outro impacto expressivo em razão da extensa área ocupada, que em muitos casos pode causar desmatamento da região e alteração da vegetação nativa.

Assim, análises criteriosas, como a da área onde será instalada a planta e do uso de matérias-primas alternativas, a exemplo daquelas provenientes de reciclagem, devem ser priorizadas a fim de minimizar tais impactos.

Os demais impactos também são importantes de serem analisados em busca de formas de minimizá-los. A vantagem do sistema é que, quando estiver operando, terá uma quantidade menor de poluentes atmosféricos em comparação aos sistemas que operam com diesel, responsáveis por expressivas emissões de $\mathrm{SO}_{\mathrm{x}}, \mathrm{CO}, \mathrm{CO}_{2}, \mathrm{NO}_{\mathrm{x}}$ e particulados.

\section{CONCLUSÕES}

O presente trabalho apresentou uma alternativa mais sustentável para a geração de eletricidade nas comunidades isoladas da Região Norte do Brasil. Apesar de apresentar um alto investimento comparado com os sistemas que operam com combustível fóssil, o recurso energético consumido são resíduos agrícolas,

Tabela 2 - Principais indicadores do sistema de biodigestão proposto.

\begin{tabular}{l|c}
\hline VPL (TMA 12\%) & US\$ 850.740 \\
\hline VPL (TMA 15\%) & US\$556.867 \\
\hline TIR & $24,92 \%$ \\
\hline Número de domicílios atendidos pela tecnologia proposta & 6.358 \\
\hline Porcentagem de atendimento pela tecnologia proposta & $100 \%$ \\
\hline Tempo de vida da planta & 20 anos \\
\hline Tempo operacional & 8.322 horas \\
\hline
\end{tabular}

VPL: valor presente líquido; TMA: taxa mínima de atratividade; TIR: taxa interna de retorno. Fonte: elaborada pelos autores. assim, o custo envolve apenas o transporte dessa matéria. O contrário ocorre com o diesel, que tem seu preço no mercado instável e necessita de uma complexa logística para chegar às comunidades isoladas.

Os impactos ambientais da construção da planta mostram que se deve focar a área que será ocupada para não causar danos à vegetação nativa. Quanto aos recursos minerais utilizados, obteve-se um impacto também expressivo. Assim, há a necessidade de buscar alternativas para uma construção a mais sustentável possível, com matérias-primas alternativas.

Tabela 3 - Inventário de ciclo de vida para a construção de uma planta de digestão anaeróbica.

Quantidade Unidade

Produto

\begin{tabular}{|c|c|c|}
\hline Planta de digestão anaeróbica & 1 & Unidade \\
\hline \multicolumn{3}{|l|}{ Sub-produtos/resíduos } \\
\hline Polietileno/polipropileno residual & 25,50 & $\mathrm{~kg}$ \\
\hline Poliestireno residual & 342 & $\mathrm{~kg}$ \\
\hline Resíduos de policloreto de vinila & 49,50 & $\mathrm{~kg}$ \\
\hline Resíduos de concreto armado & 179.280 & $\mathrm{~kg}$ \\
\hline Resíduos de borracha & 180 & $\mathrm{~kg}$ \\
\hline Resíduos de madeira & $2.741,60$ & $\mathrm{~kg}$ \\
\hline \multicolumn{3}{|l|}{ Extração da natureza } \\
\hline Ocupação, área industrial & 2.220 & $\mathrm{~m}^{2}$.ano \\
\hline Transformação para área industrial & 111 & $\mathrm{~m}^{2}$ \\
\hline \multicolumn{3}{|l|}{ Extração da esfera tecnológica } \\
\hline Concreto & 78,55 & $\mathrm{~m}^{3}$ \\
\hline Cobre & 75 & $\mathrm{~kg}$ \\
\hline Madeira laminada colada & 5,53 & $m^{3}$ \\
\hline Polietileno de alta densidade & 25,5 & $\mathrm{~kg}$ \\
\hline Poliestireno de alto impacto & 342 & $\mathrm{~kg}$ \\
\hline Polivinilcloreto polimerizado em emulsão & 6,31 & $\mathrm{~kg}$ \\
\hline Policloreto de vinilo, polimerizado em suspensão & 43,18 & $\mathrm{~kg}$ \\
\hline Aço reforçado & 6.480 & $\mathrm{~kg}$ \\
\hline Aço cromo laminado a quente & 780 & $\mathrm{~kg}$ \\
\hline Borracha sintética & 180 & $\mathrm{~kg}$ \\
\hline
\end{tabular}

Fonte: elaborada pelos autores

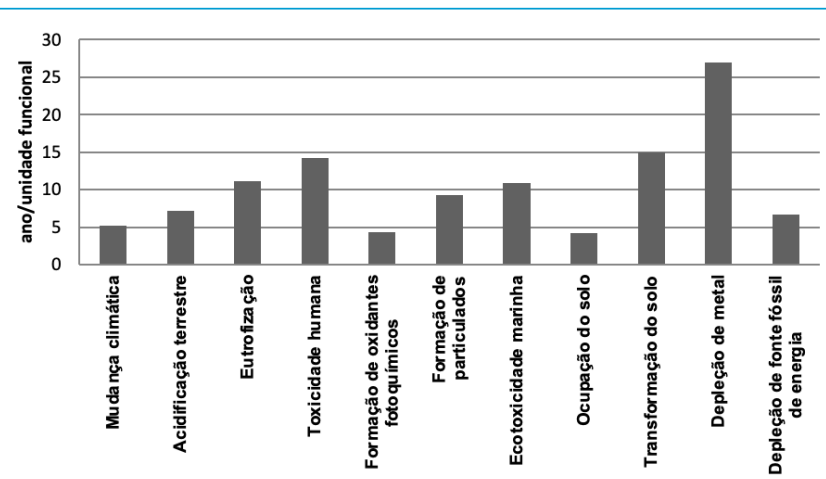

Fonte: elaborada pelos autores

Figura 3- Categorias de impacto obtidas na construção de uma planta de biodigestão 


\section{CONTRIBUIÇÕES DOS AUTORES}

Renó, M. L. G.: Conceituação, Curadoria de Dados, Análise Formal, Investigação, Administração do Projeto, Supervisão, Escrita — Revisão e Edição. Torres, P. J. P.:

Conceituação, Curadoria de Dados, Análise Formal, Investigação, Administração do Projeto, Supervisão, Escrita — Revisão e Edição. Marques, T. E.: Conceituação, Curadoria de Dados, Análise Formal, Investigação, Administração do Projeto, Supervisão, Escrita - Revisão e Edição. Ribeiro, N. S.: Metodologia, Validação, Escrita - Primeira Redação.

\section{REFERÊNCIAS}

AGÊNCIA NACIONAL DE ENERGIA ELÉTRICA (ANEEL). Matriz Energética do Brasil USINAS do tipo Petróleo em Operação. ANEEL, 2018. Disponível em: https://www.aneel.gov.br/documents/656877/14854008/Boletim+de+1 nforma\%C3\%A7\%C3\%B5es+Gerenciais+-+4\%C2\%BA+trimestre+de+2018/3 6e91555-141a-637d-97b1-9f6946cc61b3. Acesso em: 25 ago. 2021.

AMARAL, A.C.; KUNZ, A.; STEINMETZ, R.L.R.; SCUSSIATO, L.A.; TÁPPARO, D.C.; GASPARETO, T.C. Influence of solid-liquid separation strategy on biogas yield from a stratified swine production system. Journal of Environmental Management, v. 168, p. 229-235, 2016. https://doi.org/10.1016/j. jenvman.2015.12.014

ASSOCIAÇÃO BRASILEIRA DE NORMAS TÉCNICAS (ABNT). NBR ISO 14040: Gestão Ambiental - Avaliação do Ciclo de Vida - Princípios e estrutura. Rio de Janeiro: ABNT, 2009. Disponivel em: https://www.abntcatalogo.com.br/ norma.aspx?|D=316462. Acesso em: 9 jan. 2019.

BRITO NETO, O.B. Atendimento de energia elétrica domiciliar para comunidades isoladas de baixa potência do interior do estado do Pará através de um gaseificador de $1 \mathrm{~kW}$. 77f. Dissertação (Mestrado) Universidade Federal do Pará, Belém, 2006.

CARAPINHA, L.C.M. Efeito de alguns pré-tratamentos na digestão anaeróbia mesofílica de resíduos de casca de batata. 205f. Dissertação (Mestrado) Universidade Nova de Lisboa, Lisboa, 2012.
COGAN, M.; ANTIZAR-LADISLAO, B. The ability of macroalgae to stabilise and optimise the anaerobic digestion of household food waste Biomass and Bioenergy, v. 86, p. 146-155, 2016. https://doi.org/10.1016/j. biombioe.2016.01.021

MANI, J.S.; SUNDARAM, K.C.; DAS, K.C. Process simulation and modeling: Anaerobic digestion of complex organic matter. Biomass and Bioenergy, $\mathrm{V}$. 93, p. 158-167, 2016. https://doi.org/10.1016/j.biombioe.2016.07.018

ONG, M.D.; WILLIAMS, R.B.; KAFFKA, S.R. Comparative assessment of technology options for biogas clean-up. Davis: Ed. University of California, 2014. $161 \mathrm{p}$

SEADI, T.A. Biogas from AD-BIOEXELL Training Manual. Esbjerg: Ed. University of Southern Denmark, 2008. 88 p.

TORRES, P.J.P. Avaliação técnico-econômica de diferentes tecnologias de geração de eletricidade para o aproveitamento energético de resíduos de biomassa em comunidades isoladas. 236f. Dissertação (Mestrado) Universidade Federal de Itajubá, Itajubá, 2017.

ZIZLAVSKY, O. Net present value approach: method for economic assessment of innovation projects. In: 1INTERNATIONAL SCIENTIFIC CONFERENCE; ECONOMICS AND MANAGEMENT, 19., 2014. Anais [...]. Riga: ICEM, 2014. p. 23-25. 